\title{
Antimicrobial activity of silver composites obtained from crosslinked polystyrene with polyHIPE structures
}

\author{
Roberta Trovão Santos ${ }^{1}$ (D), Nathália Smith Santos ${ }^{1}$ (D), Mirian Araújo de Oliveira1 ${ }^{1}$, \\ Fernanda de Andrade Buás Campeão ${ }^{1}$ (D), Maria Aparecida Larrubia Granado Moreira Rodrigues Mandu² (D), \\ Mônica Regina Costa Marques ${ }^{3}$ (D) and Luciana da Cunha Costa ${ }^{1 *}$
}
1Programa de Pós-graduação em Ciência e Tecnologia Ambiental, Centro Universitário Estadual da Zona Oeste - UEZO, Rio de Janeiro, RJ, Brasil

${ }^{2}$ Departamento de Controle de Qualidade de Águas, Companhia Estadual de Águas e Esgoto - CEDAE/RJ, Rio de Janeiro, RJ, Brasil

3Programa de Pós-graduação em Química, Universidade do Estado do Rio de Janeiro - UERJ, Rio de Janeiro, RJ, Brasil

*lucianacosta@uezo.edu.br

\begin{abstract}
The literature reports several potential applications of polymers prepared with high internal phase emulsions (HIPEs). However, the evaluation of these materials as supports for antimicrobial agents has not been explored. In this work, silver composites based on polyHIPEs were prepared. Initial studies indicated that these materials can be efficient to prevent biofilm formation. The silver composites were prepared in three steps. First, HIPEs based on styrene-divinylbenzene were polymerized by aqueous suspension polymerization. These particles showed surface areas of 18 and $48 \mathrm{~m}^{2} / \mathrm{g}$. These polyHIPEs were sulfonated with concentrated sulfuric acid or acetyl sulfate and showed cation exchange capacities of 4.03 and $5.07 \mathrm{meq} / \mathrm{g}$ respectively. The sulfonated material was impregnated with silver ions, followed by reduction of the ions to prepare silver composites. These composites showed inhibition halos against $E$. coli and P. aeruginosa. and did not present adhesion of bacterial cells of $K$. variicola and $S$. aureus on their surface.
\end{abstract}

Keywords: high internal phase emulsions, polyHIPEs, silver composites, styrene-divinylbenzene copolymers, biocidal polymers.

How to cite: Santos, R. T., Santos, N. S., Oliveira M. A., Campeão, F. A. B., Mandu, M. A. L. G. M. R., Marques, M. R. C., \& Costa, L. C. (2021). Antimicrobial activity of silver composites obtained from crosslinked polystyrene with polyHIPE structures. Polimeros: Ciência e Tecnologia, 31(3), e2021030. https://doi.org/10.1590/0104-1428.20210005

\section{Introduction}

The literature indicates that high internal phase emulsions (HIPEs) (containing more than $74 \mathrm{vol} \%$ of internal phase) can be employed as templates for porous polymers, generating polyHIPE structures ${ }^{[1]}$. Despite a large number of publications and patents involving the preparation of polyHIPE structures, only a few of these works involve polymerization of these HIPEs by aqueous suspension polymerization (Hainey et al. ${ }^{[2]}$; Cameron et al. ${ }^{[3]}$; Desforges et al. ${ }^{[4]}$; Stefanec and Krajnc ${ }^{[5,6]}$; Yang et al. ${ }^{[7]}$; Mert and Hildirim ${ }^{[8]}$; Cui et al..$^{[9]}$; Torquato et al. ${ }^{[10]}$ ) and US patents $5,583,162^{[11]}, 6,048,908^{[12]}, 6,100,306^{[13]}$ and $\left.6,218,440^{[14]}\right)$. The polymerization of HIPEs by employing aqueous suspension polymerization, also referred as waterin-oil-in-water polymerization $(\mathrm{W} / \mathrm{O} / \mathrm{W})$, can generate spherical particles with an open porous morphology with pores connecting larger cavities (windows) ${ }^{[10]}$. This type of morphology can favor access of reactants and products through the internal structure of the polymer ${ }^{[15,16]}$, contributing to reduction of mass transfer limitations, especially intraparticle diffusion, and consequently allow the development of more

efficient materials. The application of these polyHIPEs is widespread in many areas ${ }^{[15-18]}$, such as supports for catalysts ${ }^{[15]}$, $\mathrm{CO}_{2}$ capture ${ }^{[16]}$, stationary phase for preconcentration of PAHs in environmental water samples ${ }^{[17]}$, and development of enzymatic reactors based on immobilization of enzymes on these polymers ${ }^{[18]}$.

Crosslinked porous copolymers have been used as supports for several antimicrobial groups such as ammonium and phosphonium quaternary groups, charge transfer complexes involving iodine and quaternary ammonium groups, N-halamines, sulfo-derivatives and metal particles ${ }^{[19]}$. Antimicrobial polymers based on silver composites and nanocomposites have potential applications for the inhibition of biofilm formation ${ }^{[20]}$. Among the studies involving the preparation of silver composites from crosslinked copolymers can be cited the works of Gangadharan et al. ${ }^{[21]}$ Santa Maria et al. ${ }^{[22]}$, Mthombeni et al. ${ }^{[23]}$ and Mandu et al. ${ }^{[20]}$. In these studies, the antimicrobial activity of the final products was evaluated by different strategies. Gangadharan et al. ${ }^{[21]}$ developed a silver nanocomposite through impregnation 
of silver nanoparticles in microspheres of methacrylic acid and divinylbenzene, prepared by aqueous suspension polymerization. The antimicrobial activity of this material was evaluated against $E$. coli, P. aeruginosa, B. subtilis and $S$. aureus employing the plate method and in test tubes. Santa Maria et al. ${ }^{[22]}$, Mthombeni et al. ${ }^{[23]}$ and Mandu et al. ${ }^{[20]}$ prepared silver composites from commercial sulfonic resins (Lewatit VPOC1800, Amberlyst 15WET, Amberlite IR-120, respectively). The method of impregnation of silver nanoparticles in these resins was based on exchange of $\mathrm{H}^{+}$ions by $\mathrm{Ag}^{+}$ ions followed by chemical reduction of these ions. Santa Maria et al. ${ }^{[22]}$ evaluated the antimicrobial activity of these materials against $E$. coli in tests employing micro syringes. In turn, Mthombeni et al. ${ }^{[23]}$ evaluated the antimicrobial activity of these silver nanocomposites against $E$. coli in macroscale column experiments. Mandu et al. ${ }^{[20]}$ evaluated the antimicrobial activity of silver composites against $E$. coli, $P$. aeruginosa and $S$. aureus through plate, batch, and column experiments. From the column experiments, also realized on a macro scale, they determined the breakthrough point and working biocidal activity. However, in these works, no tests were performed to simulate the ability of the final products to inhibit biofilm formation.

Literature data show that polyHIPEs have not been investigated as supports for antimicrobial groups. Thus, here we report a strategy to prepare silver composites from polyHIPEs of styrene-divinylbenzene (Sty-DVB) containing sulfonic groups. The antimicrobial activity of these silver composites was evaluated by employing inhibition halo tests against two Gram-negative bacteria of medical importance (Escherichia coli and Pseudomonas aeruginosa). The silver composites were also evaluated regarding bacterial adsorption and adhesion employing the bacteria Klebsiella variicola (Gram-negative) and Staphylococcus aureus (Gram-positive) to simulate inhibition on biofilm formation.

The sulfonation of polyHIPEs has been sparsely studied, by employing concentrated sulfuric acid ${ }^{[24,25}$ or lauroyl sulfate in cyclohexane ${ }^{[26]}$ as sulfonating agents. Thus, in the present work the sulfonation of the polyHIPE particles was studied by using concentrated sulfuric acid or acetyl sulfate as sulfonating agents (in a comparative study), aiming to learn the effect of the type of sulfonating agent on the morphology of the polyHIPEs and cation exchange capacity of the sulfonated particles.

All steps of this work are shown schematically in Figure 1.

\section{Materials and Methods}

\subsection{Materials}

Styrene (Sty) and divinylbenzene (DVB) (donated by Nitriflex Indústria e Comércio S.A.) were used after acid-base extraction by using $5 \% \mathrm{w} / \mathrm{v} \mathrm{NaOH}$ aqueous solution. 2,2-azobis-isobutyronitrile (AIBN) was acquired from Mig Quimica and used after recrystallization with methanol. Poly(vinyl alcohol) (PVA) 224 (hydrolysis degree of 87-89\%) was donated by Kurary Inc. and polyvinylpyrrolidone (PVP) (Mw $1,300.000$ ) was acquired from Fluka. The microorganisms used in this work were Escherichia coli (ATCC 11229), Pseudomonas aeruginosa (ATCC 15442), Klebsiella variicola (ATCC 31488) and Staphylococcus aureus (ATCC 25923). The culture media used were Mueller-Hinton II broth (MHII) (BBL), Mueller-Hinton II agar (Kasvi), and plate count agar (PCA) (Neogen). Other reagents and solvents were purchased from Sigma-Aldrich and used as received.

\subsection{Synthesis of Sty-DVB polyHIPEs}

First, high internal phase emulsions (HIPEs) of Sty-DVB were prepared in a round-bottom three-necked flask with $250 \mathrm{~cm}^{3}$ capacity, fitted with a mechanical stirrer reactor. The organic phase was composed of Sty $(0.072 \mathrm{~mol}), \mathrm{DVB}$ $(0.029 \mathrm{~mol}), \operatorname{AIBN}(0.0009 \mathrm{~mol})$ and Span $80(0.0053 \mathrm{~mol})$. The aqueous phase (AP) was composed of $\mathrm{NaCl}(0.67 \mathrm{~g})$, potassium persulfate $(0.45 \mathrm{~g})$ and distilled water $(33 \mathrm{~mL})$. The aqueous phase was dripped through an addition funnel into the organic phase (35 minutes) under mechanical stirring

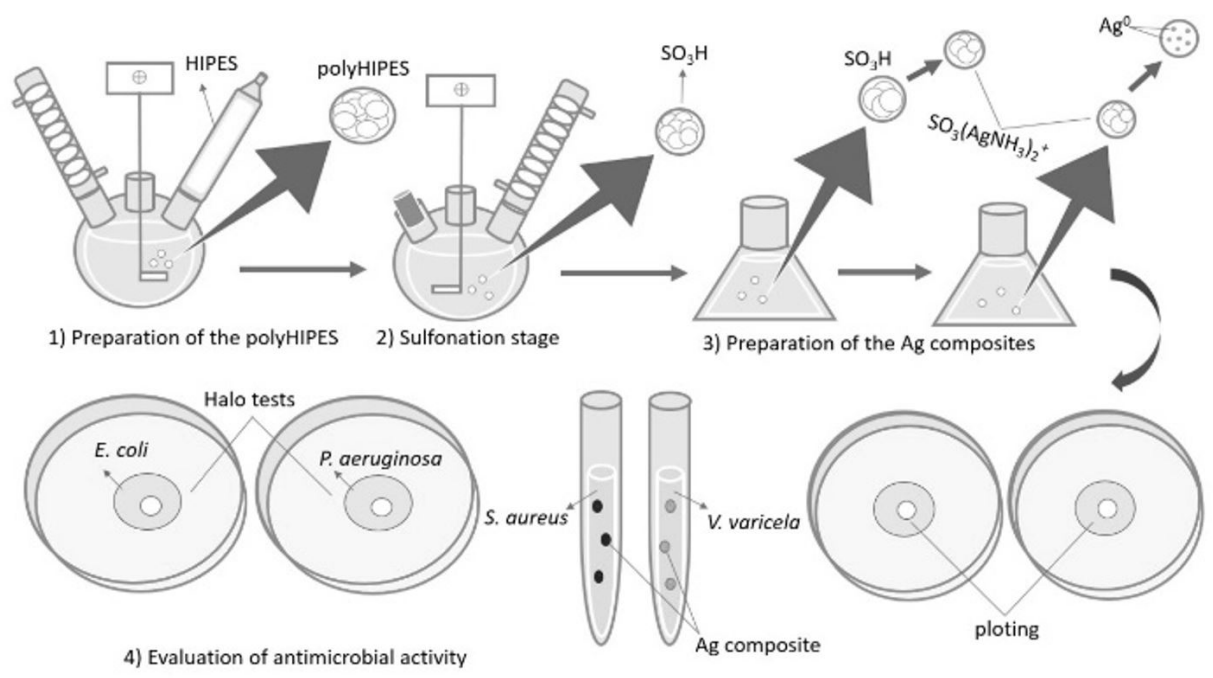

Figure 1. Schematic representation of all stages of the experiment. 
at $250 \mathrm{rpm}$. In the second stage, HIPEs (as viscous white solutions) were polymerized by aqueous suspension, forming polyHIPEs structures. The aqueous phase was prepared using PVP (1.98 g) or PVA (1.98 g) as suspending agent, $\mathrm{NaCl}$ $(1.49 \mathrm{~g})$ and distilled water $\left(99.4 \mathrm{~cm}^{3}\right)$, and then transferred to a round-bottom three-necked flask with $500 \mathrm{~cm}^{3}$ capacity. The HIPE was added to the aqueous phase (pre-heated to $80{ }^{\circ} \mathrm{C}$ ) dropwise for 30 minutes under mechanical stirring at $150 \mathrm{rpm}$. The reaction mixture remained for 24 hours in these conditions at $80{ }^{\circ} \mathrm{C}^{[4-6,10]}$. After preparation, the particles were treated with hot water, ethanol and acetone to remove residues. After washing, the polyHIPEs were oven dried for 24 hours at $60^{\circ} \mathrm{C}$.

\subsection{Sulfonation of Sty-DVB polyHIPEs}

The polyHIPE composed of Sty-DVB prepared with PVP as stabilizer was sulfonated with sulfuric acid or acetyl sulfate to promote silver ion anchorage in the silver impregnation step (Figure 1). The first sulfonation was carried out with sulfuric acid. PolyHIPE (4.0 g) was previously soaked in 1.2 dichloroethane $\left(18.5 \mathrm{~cm}^{3}\right)$ for 2.5 hours. After this period, the material was sulfonated with sulfuric acid (95-99\%) $(1.13 \mathrm{~mol})$ in a $500 \mathrm{~cm}^{3}$ flask coupled to a mechanical stirrer and reflux condenser, and was stirred at a rate of $90 \mathrm{rpm}$ at $90{ }^{\circ} \mathrm{C}$ for 24 hours. Previous swelling of the particles by soaking with 1.2 dichloroethane allowed greater access of the reactant sulfuric acid to the internal structure of the polymeric beads, aiming to preserve their spherical morphology ${ }^{[27]}$. The second sulfonation method was based on employment of acetyl sulfate as sulfonating agent ${ }^{[28]}$. This reagent was prepared employing acetic anhydride $(1.13 \mathrm{~mol})$, anhydrous dichloromethane $(0.39 \mathrm{~mol})$ and concentrated sulfuric acid (1.13 mol) under $\mathrm{N}_{2}$ atmosphere. PolyHIPE (4.0 g) was swollen in anhydrous dichloromethane $\left(30 \mathrm{~cm}^{3}\right)$ for 1 hour under $\mathrm{N}_{2}$ atmosphere in a round-bottom flask. After this period, the sulfonating agent prepared in the previous step was added to the flask. The reaction mixture was kept at a constant temperature of $40{ }^{\circ} \mathrm{C}$ for 24 hours under stirring at $90 \mathrm{rpm}$. The sulfonated polyHIPEs were filtered under reduced pressure, washed with distilled water to neutral $\mathrm{pH}$ and oven dried at $60{ }^{\circ} \mathrm{C}$ for 24 hours.

\subsection{Impregnation of silver in sulfonated Sty-DVB polyHIPES}

The impregnation of silver nanoparticles in polymers was performed according to the descriptions of Mandu et al. ${ }^{[20]}$, Santa Maria et al. ${ }^{[22]}$ and Gangadharan et al. ${ }^{[21]}$, with modifications. Both sulfonated polyHIPEs (1 g) were treated with $\mathrm{AgNO}_{3}$ (aqueous solution of $0.1 \mathrm{~mol} \mathrm{~L}^{-1}, 10 \mathrm{~mL}$ ) for 48 hours in a sealed environment protected from light. After filtration and washing with water, the reduction of $\mathrm{Ag}^{+}$to $\mathrm{Ag}^{0}$ ions was performed by applying $4.7 \mathrm{~g}$ of hydroxylamine hydrochloride and $2 \mathrm{~mol} \mathrm{~L}^{-1} \mathrm{NH}_{4} \mathrm{OH}$ solution (to maintain the $\mathrm{pH}$ at 12.0) and a solution of distilled water $\left(50 \mathrm{~cm}^{3}\right)$, gelatin $(1.5 \mathrm{~g})$ and hydroxyethyl cellulose (1.5 g) (Figure 1). The mixture of gelatin and HEC was used as colloid protector, aiming to reduce the reaction of $\mathrm{Ag}^{+}$ions in the polymer matrix in controlled form ${ }^{[29]}$. The composite produced was washed thoroughly with deionized distilled water $\left(60{ }^{\circ} \mathrm{C}\right)$, then ethanol $\left(50 \mathrm{~cm}^{3}\right)$, and dried at $60{ }^{\circ} \mathrm{C}$ for 24 hours.

\subsection{Characterization of the polymers}

Sty-DVB polyHIPEs were characterized regarding apparent density (ASTM D1895-69) ${ }^{[30]}$ by optical microscopy (Olympus BX51M) and scanning electron microscopy (SEM) (JEOL-JSM 6460 LV), and the specific area, pore volume and pore diameter were determined through nitrogen physisorption (Micromeritics ASAP 2020 apparatus) following the BET and BJH equations ${ }^{[31]}$, and the particle size distribution was ascertained (Malvern Hydro 2000S model). Sulfonation was accompanied by determination of cation exchange capacity ${ }^{[32]}$. The FT-IR spectra of the all polymers (KBr pellets) were recorded with a Perkin-Elmer Spectrum One spectrometer (4 scans, $4 \mathrm{~cm}^{-1}$ resolution). TG and DTG curves of the copolymers were obtained using a TA Q50 instrument in the temperature range of $50-600^{\circ} \mathrm{C}$ $\left(20^{\circ} \mathrm{C} \mathrm{min}^{-1}\right)$ under $\mathrm{N}_{2}$ atmosphere $\left(60 \mathrm{~mL} \mathrm{~min}^{-1}\right)$.

\subsection{Evaluation of antimicrobial activity}

Antimicrobial evaluation of silver composites was performed by inhibition halo tests to verify the ability of polymers to inhibit growth of the bacteria $E$. coli and P. aeruginosa ${ }^{[33]}$. Petri dishes (100 $\mathrm{mm}$ diameter) were filled with $30 \mathrm{~cm}^{3}$ of $\mathrm{MH}$ II agar. Bacterial suspensions in MHII medium with $1 \times 10^{8} \mathrm{CFU} / \mathrm{mL}$ were used to inoculate the entire sterile surface of the agar in the Petri dishes using sterile swabs. The polymers were then inserted into $5 \mathrm{~mm}$ diameter holes in the inoculated MHII agar. The dishes were incubated in a culture oven at $37^{\circ} \mathrm{C}$ for 24 hours. The test was performed in triplicate. After the incubation period, the halos of the microbial inhibition zones were measured, corresponding to the shortest distance between the outer surface of the well and the beginning of the microbial growth region. They were measured with a millimeter ruler.

Silver composites also were evaluated in relation to bacterial adsorption and adhesion ${ }^{[21]}$ aiming to evaluate potential applications to inhibit biofilm formation. This study was conducted by employing suspensions of $K$. variicola and $S$. aureus. Suspensions of these bacteria $\left(10^{6} \mathrm{CFU} / \mathrm{mL}\right)$ were inoculated using nutrient medium in test tubes. Silver composites $(0.2 \mathrm{~g})$ were also transferred to these tubes and kept in contact with the bacterial suspensions for $24 \mathrm{~h}$ at $45^{\circ} \mathrm{C}$. After this, the silver composite was filtered by using sterile syringes containing filter paper and washed with sterile deionized water. The silver composite was plated on nutrient agar (PCA medium) and incubated for $48 \mathrm{~h}$ at $45^{\circ} \mathrm{C}$ to check bacterial adsorption/adhesion. For statistical analysis, the PAST v2.17 data analysis package was used and the Kruskal-Wallis test for nonparametric data was applied, with $\mathrm{p}<0.05$ being considered statistically significant.

\section{Results and Discussions}

\subsection{Synthesis of polyHIPES}

HIPEs based on styrene-divinylbenzene (Sty-DVB) were suspended in an aqueous suspension phase containing as stabilizer poly(vinyl alcohol) (PVA) or polyvinylpyrrolidone (PVP) to prepare polyHIPEs. Optical microscopic images of these polyHIPEs (Figure 2) showed the presence of spherical particles and undefined shapes formed by using both stabilizers. 
The formation of agglomerates by using both stabilizers was also observed, even after intense washing of the particles with hot water. The polyHIPE N3, prepared by using PVA as stabilizer, showed a larger distribution of particles sizes (Figure 3c) than the polyHIPE N2, synthesized by using PVP as stabilizer. The optical microscopic images of the polyHIPE N3 revealed the presence of smaller particles and agglomerations, and also a small group of larger particles, some spherical and others stick-shaped (Figure 2d and Figure S1). However, the particle size curve for this material (Figure 3c) did not show a bimodal size distribution for these particles, not corroborating the optical microscopic data. According to Budhlall et al. ${ }^{[34]}$ PVA and PVP adopted varied conformations on the aqueous phase, related to the mechanism of solvating the polymeric chains, which is dependent on molecular mass and hydrolysis degree of these stabilizers. These variations cause significant modifications in particle nucleation mechanisms during the polymerization process. Considering this, it is also possible to suppose that both the process of dispersion up and coalescing in the early stage of the polymerization, and the agglomeration process during formation of the macroscopics structures (generated by w/o/w polymerization) were influenced by the conformations of the stabilizers in the aqueous phase. From a simpler point of view, it is possible to suppose that higher viscosity of the aqueous solution prepared using PVP as a stabilizer (Mw 1,300.000) generated more compact droplets during early stages of the polymerization, in turn generating more compact particles.

SEM micrographs of these materials (Figure 2) indicated that the polymer prepared with the stabilizer PVP had a more porous structure. This observation was confirmed by data of surface area and pore volume of these two materials (Table 1). Probably more voids between polymeric domains were formed when PVP was used as the stabilizer, generating more porous structures ${ }^{[35]}$. The influence of the type of stabilizer on the morphology of the polyHIPEs prepared by aqueous suspension has not yet been explored in literature. Thus, more studies are necessary to confirm these data.

The polyHIPE particles showed type IV isotherms (Figure 3$)^{[31,36]}$. It was visually clear that hysteresis was low between the adsorption and desorption processes, associated with capillary condensation on mesopores structures. The initial portion of this isotherm is related with monolayermultilayer adsorption ${ }^{[31]}$. The low content of $\mathrm{N}_{2}$ adsorbed at low relative pressure indicates that this material did not contain micropores in its structure ${ }^{[36]}$. The hysteresis loop profiles can be classified as $\mathrm{H} 3$ type (or B type) (considered intermediate between hysteresis type $\mathrm{H} 1$ and H4). This type of hysteresis loop is characteristic of aggregates of plate-like particles, giving rise to slit-shaped pores ${ }^{[31]}$.

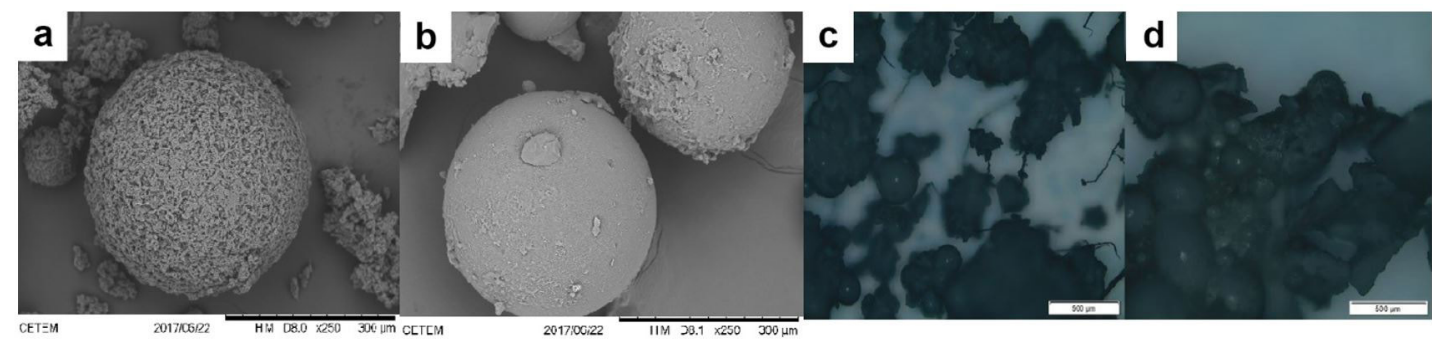

Figure 2. (a, b) SEM micrographs of the polyHIPEs N2 and N3, respectively. Magnifications of 250x; (c, d) Optical microscopic images of the polyHIPEs N2 and N3, respectively. Magnifications of 50x.
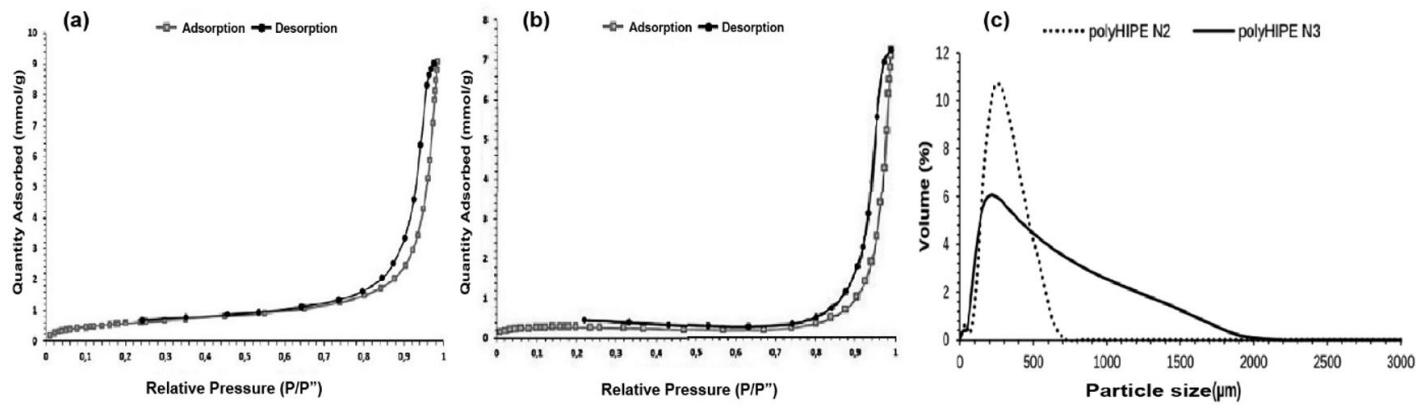

Figure 3. (a) $\mathrm{N}_{2}$ adsorption-desorption isotherms of polyHIPE N2; (b) $\mathrm{N}_{2}$ adsorption-desorption isotherms of polyHIPE N3; (c) Particle size distribution of polyHIPE N2 and N3.

Table 1. Data on apparent density, surface area, pore volume and pore diameter of polyHIPEs of Sty-DVB N2 and N3.

\begin{tabular}{|c|c|c|c|c|c|}
\hline PolyHIPEs & Stabilizer & dap $\left(\mathrm{cm}^{3} / \mathrm{g}\right)$ & $\mathrm{S}\left(\mathrm{m}^{2} / \mathrm{g}\right)$ & $V p\left(\mathrm{~cm}^{3} / \mathrm{g}\right)$ & $\mathbf{D}(\AA)$ \\
\hline $\mathrm{N} 2$ & PVP & 0.36 & 48.4 & 0.32 & 214.9 \\
\hline N3 & PVA & 0.27 & 18.3 & 0.25 & 272.5 \\
\hline
\end{tabular}

dap: apparent density; S: specific surface area; Vp: pore volume; D: pore diameter; PVA: polyvinyl alcohol; PVP: polyvinyl pyrrolidone. 
The morphology of the polyHIPEs prepared by polymerization of HIPEs via aqueous suspension has not been sufficiently studied by $\mathrm{N}_{2}$ adsorption. Comparison between the results found in this work and data reported by Cui et al ${ }^{[9]}$ shows similarity between the $\mathrm{N}_{2}$ adsorptiondesorption isotherms. However, the microspheres prepared by Cui et al. ${ }^{[9]}$ had specific surface areas varying between 3 and $4 \mathrm{~m}^{2} / \mathrm{g}$ whereas the microspheres synthesized in this study had surfaces areas of 18 and $48 \mathrm{~m}^{2} / \mathrm{g}$. Probably this difference was related to variations in monomeric composition. PolyHIPEs obtained in this work were composed of Sty and DVB while the polyHIPEs prepared by Cui et al. ${ }^{[9]}$ were composed of Sty, DVB, stearyl methacrylate (SMA) and n-butyl acrylate (BA). It is plausible to suppose that alterations of monomer polarity will generate modifications in the phase separation mechanism and the phase separation stage, generating beads with lower porosity ${ }^{[35]}$.

\subsection{Sulfonation of polyHIPES}

PolyHIPE N2 prepared with PVP as stabilizer was chosen for sulfonation reactions due to its higher specific surface area and pore volume. It was submitted to sulfonation with concentrated sulfuric acid or acetyl sulfate in order to introduce $\mathrm{SO}_{3} \mathrm{H}$ groups in the polymeric matrix. After sulfonation reaction the particles showed color ranging from dark brown to black. Oliveira et al. ${ }^{[28]}$ reported that acetyl sulfate is a better sulfonating agent than sulfuric acid because it contributes to maintaining the spherical morphology of the particles. In this work, alterations of morphology of the particles related to the type of sulfonating agent were not clearly observed by optical microscopy, since both stabilizers generated undefined particles in addition to spherical particles and agglomerates. We observed that part of the polyHIPEs kept their spherical morphology even after sulfonation with sulfuric acid (Figure S2).

FT-IR analysis of polyHIPEs after sulfonation with both sulfonating agents (Figure 4) revealed the presence of new bands at $1216 \mathrm{~cm}^{-1}$, attributed to asymmetric stretching vibration of the $\mathrm{S}=\mathrm{O}$ bonds in the sulfonate group $\left(\mathrm{H}_{3} \mathrm{O}^{+} \mathrm{SO}_{3} \text { - group }\right)^{[28,37]}$, besides a pronounced increase of bands at $3400 \mathrm{~cm}^{-1}$ due to hydrogen bonding between sulfonic groups (polar) and water molecules (moist) ${ }^{[37]}$, confirming the occurrence of both sulfonation reactions. These new bands were more accentuated in the FT-IR spectrum of polyHIPE sulfonated with sulfuric acid, indicating that this sulfonation method was more thorough.

After sulfonation with both sulfonating agents, the polyHIPEs showed three stages of decomposition (Table 2), related to water loss, decomposition of sulfonic groups and degradation of the entire carbon chain ${ }^{[38]}$. The content of residue was higher in polyHIPE sulfonated with sulfuric acid, also indicating that this sulfonation was more efficient. PolyHIPE sulfonated with sulfuric acid showed higher cation exchange capacity (CEC) than polyHIPE sulfonated with acetyl sulfate (Table 3 ). This result agrees with those obtained by FT-IR and thermogravimetry and indicates that
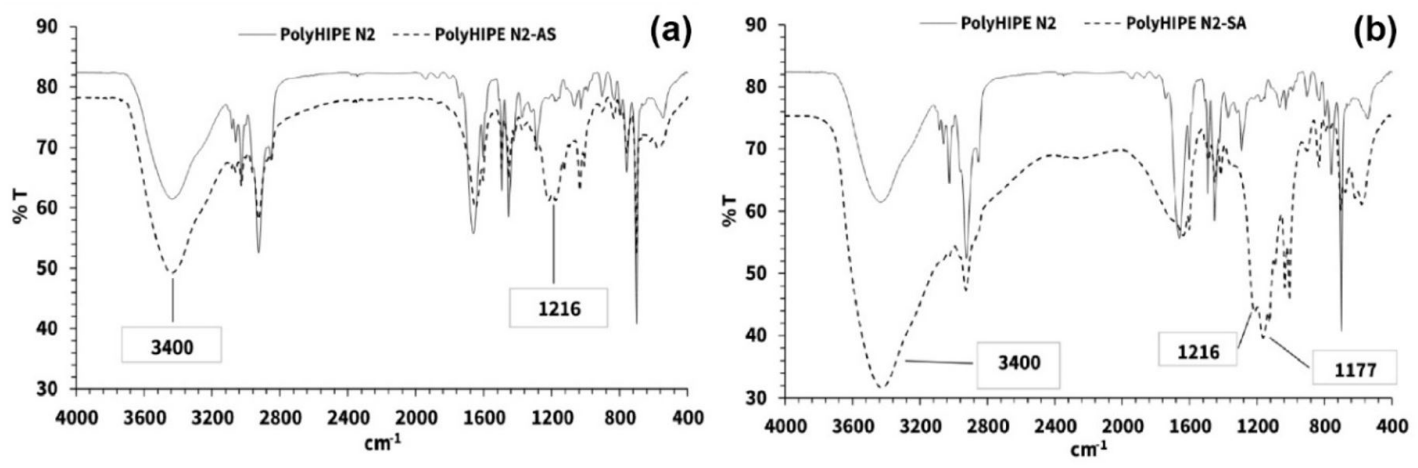

Figure 4. FT-IR spectra of unmodified polyHIPE (polyHIPE N2), polyHIPE sulfonated with acetyl sulfate (polyHIPE N2-AS (a)) and polyHIPE sulfonated with sulfuric acid (polyHIPE N2-SA (b)).

Table 2. Thermal characteristics of the polyHIPE N2, polyHIPE N2 sulfonated with sulfuric acid (polyHIPE N2-SA), polyHIPE N2 sulfonated with acetyl sulfate (polyHIPE N2-AS), silver composites derived from these two materials (based on work of Simplicio et al. ${ }^{[38]}$ ).

\begin{tabular}{lccccccc}
\hline \multicolumn{1}{c}{ Material } & $\mathbf{T}_{\text {onset }}(\mathbf{1})\left({ }^{\mathbf{0}} \mathbf{C}\right)^{\mathbf{a}}$ & $\mathbf{T}_{\text {onset }}(\mathbf{2})\left({ }^{\mathbf{0}} \mathbf{C}\right)^{\mathbf{b}}$ & $\mathbf{T}_{\text {onset }}(\mathbf{3})\left({ }^{\mathbf{0}} \mathbf{C}\right)^{\mathbf{c}}$ & $\mathbf{R C}^{\mathbf{d}}(\mathbf{\%})$ & $\mathbf{R D}^{\mathbf{e}}(\mathbf{\%})$ & $\mathbf{I D}^{\mathbf{f}}(\mathbf{\%})$ & $\mathbf{R D}^{\mathbf{q}}(\mathbf{\%})$ \\
\hline polyHIPE N2 & 362 & - & - & 5.9 & - & - & - \\
polyHIPE N2-SA & 82 & 256 & 351 & 28.6 & 22.7 & - & - \\
polyHIPE N2-AS & 81 & 284 & 360 & 18.2 & 12.3 & - & - \\
polyHIPE N2-SA-Ag & 74 & 282 & 389 & 40.4 & 34.5 & $11.8^{\mathrm{j}}$ & $41.3^{\mathrm{k}}$ \\
polyHIPE N2-AS-Ag & 116 & 254 & 393 & 24.4 & 18.5 & $6.2^{\mathrm{j}}$ & $34.1^{\mathrm{k}}$ \\
\hline
\end{tabular}

${ }^{\mathrm{a}} \mathrm{T}_{\text {onset }}$ related with the first stage of decomposition, ${ }^{\mathrm{b}} \mathrm{T}_{\text {onset }}$ related with the second stage of decomposition, ${ }^{\mathrm{c}} \mathrm{T}_{\text {onset }}$ related with the third stage of decomposition, ${ }^{d} \mathrm{RD}$ : residue content after last stage of the decomposition, ${ }^{\mathrm{e}} \mathrm{RD}$ : Residue difference, difference of residue content between modified and unmodified polyHIPE, ${ }^{\mathrm{f}}$ Inorganic residue: Content of inorganic residue determined by difference between residue of composite and sulfonated materials, ${ }^{\mathrm{g}}$ Resistance to degradation $\%$ : Increase of thermal resistance at $700{ }^{\circ} \mathrm{C}$ (comparing sulfonated polyHIPEs and silver composites derived from these materials): resistance $\%$ : (residue $\%$ composite - residue $\%$ sulfonated material)/(residue $\%$ sulfonated material) x 100 . 
the sulfonation reaction with concentrated sulfuric acid generated structures with higher content of accessible sulfonic groups. Considering that the sulfonation with acetyl sulfate was carried out in a milder condition than the sulfonation with sulfuric acid, it is possible to suppose that the degree of sulfonation with acetyl sulfate was lower, i.e., sulfonation with sulfuric acid enabled introducing more sulfonic groups in the innermost layers of the particles. Oliveira et al. ${ }^{[28]}$ also observed that polymers sulfonated with sulfuric acid showed higher CEC than polymers sulfonated with acetyl sulfate.

Table $\mathrm{S} 1$ shows CEC values of sulfonic resins synthesized by other authors with commercial sulfonic resins ${ }^{[28,32,39-41]}$. The CEC value found for polyHIPE sulfonated with acetyl sulfate (PolyHIPE N2-AS) was more than three times higher than the CEC of the Sty-DVB copolymer sulfonated with the same sulfonating agent prepared by Oliveira et al. $(\mathrm{RM}-10)^{[28]}$. The CEC of polyHIPE sulfonated with sulfuric acid (PolyHIPE N2-AS) was higher than that of sulfonic resins prepared by Reis et al. ${ }^{[32]}$, Aguiar et al. ${ }^{[39]}$, Rezende et al. ${ }^{[40]}$ and equivalent to the CEC of the sulfonic resin prepared by Coutinho et al. ${ }^{[37]}$ and several commercial sulfonic resins used in industrial processes, such as Amberlyst 18 $8^{[39]}$, Amberlyst XN 1010 $0^{[39]}$, Amberlyst $35^{[39,41]}$ and Amberlyst $36^{[32,39,40]}$. Sulfonation reactions were conducted after swelling of the beads in 1,2-dichloroethane (a good solvent of the polymeric chains) in order to avoid cracking the beads during sulfonation and also to favor diffusion of the sulfonating agents through the structure of the polymers ${ }^{[27]}$. PolyHIPE structures are characterized by the presence of interconnecting pores and larger cavities formed during polymerization of an external phase containing monomers dispersed in an aqueous phase ${ }^{[10]}$. Probably this type of structure favored the diffusion of the sulfonating agents through the internal structure of polymers, contributing to the higher CEC values observed.

\subsection{Preparation of silver composites}

PolyHIPEs sulfonated with acetyl sulfate and sulfuric acid were submitted to impregnation with silver particles in two steps: treatment of sulfonic particles with aqueous solution of $\mathrm{AgNO}_{3}$ and reduction of $\mathrm{Ag}^{+}$to $\mathrm{Ag}^{0}$ employing hydroxylamine hydrochloride and $\mathrm{NH}_{4} \mathrm{OH}$, in the presence of gelatin and hydroxyethyl cellulose (Figure 1). Some researchers have indicated that this method introduces silver nanoparticles into the polymeric structure ${ }^{[20-23]}$. EDS spectra of silver composites showed peaks associated with elemental silver located between $2.6 \mathrm{KeV}$ and $3.6 \mathrm{KeV}$ (Figure 5). The presence of these peaks confirmed the reduction of $\mathrm{Ag}^{+}$ions present in $\left[\mathrm{Ag}\left(\mathrm{NH}_{3}\right)_{2}\right]^{+}$groups, associated with $\mathrm{SO}_{3}$ - groups, to $\mathrm{Ag}^{0[21,22]}$.

It was possible to observe small variations in the degradation profile of the composites polyHIPE N2-SA-Ag (derived from polyHIPE sulfonated with sulfuric acid) and polyHIPE N2-AS-Ag (derived from polyHIPE sulfonated with acetyl sulfate) (Table 2). For polyHIPE N2-AS-Ag, the first stage of degradation occurred at $116^{\circ} \mathrm{C}(1.6 \%$ of mass lost) while for polyHIPE N2-SA-Ag, the first step of decomposition occurred at $74{ }^{\circ} \mathrm{C}(4.8 \%$ of mass lost). This first stage of decomposition can be related with water loss, while the second and third stages are related to the degradation of sulfonic groups and polymeric matrix, respectively ${ }^{[38]}$. The silver composite polyHIPE N2-SA-Ag had more residue (40.4\%) than polyHIPE N2-AS-Ag (24.4\%). Resistance to degradation of these composites was calculated considering the difference between residue content of the composites and sulfonated polyHIPEs. The values found were $41.3 \%$ (composite polyHIPE N2-SA-Ag) and 34.1\% (composite polyHIPE N2-AS-Ag) ${ }^{[38]}$. These results allow suggesting that the composite derived from polyHIPE sulfonated with sulfuric acid contains more inorganic residue ( $\mathrm{Ag}^{0}$ content resistant to decomposition.

\subsection{Evaluation of antibacterial activity of polymers}

According to Table 4, all silver composites produced inhibition halos against Pseudomonas aeruginosa and Escherichia coli (Gram-negative bacteria), demonstrating the composites' ability to inhibit bacterial growth around silver particles. Statistical analysis of these data, performed by one-way analysis of variance, demonstrated that the

Table 3. Cation exchange capacity (CEC) of the polyHIPE sulfonated with acetyl sulfate (polyHIPE N2-AS), polyHIPE sulfonated with sulfuric acid (polyHIPE N2-SA).

\begin{tabular}{ccc}
\hline Supports & Sulfonating agents & CEC $\left(\mathbf{m e q} / \mathbf{S O}_{3} \mathbf{H} / \mathbf{g}\right)$ \\
\hline PolyHIPE N2-AS & acetyl sulfate & 4.03 \\
PolyHIPE N2-SA & Sulfuric acid & 5.07 \\
\hline
\end{tabular}

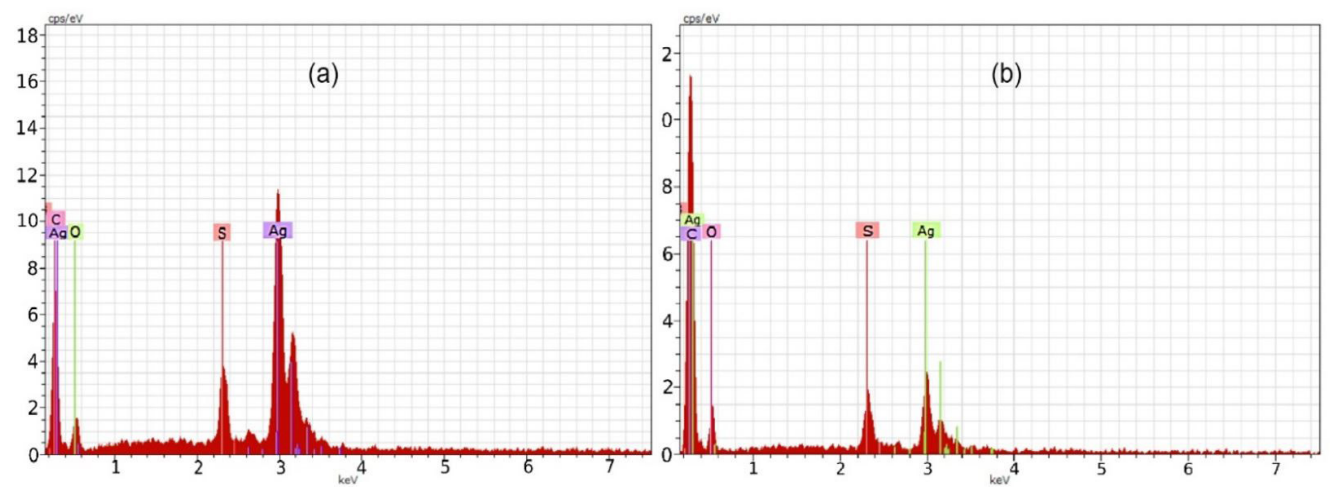

Figure 5. (a) EDS spectra of polyHIPE sulfonated with sulfuric acid; (b) EDS spectra of the polyHIPE. 
Table 4. Halo values of polymers tested on Mueller-Hinton agar against Pseudomonas aeruginosa and Escherichia coli and variable correlations by applying the Kruskal-Wallis test.

\begin{tabular}{|c|c|c|c|c|c|c|c|c|c|}
\hline \multirow{4}{*}{$\begin{array}{l}\text { Pseudomonas } \\
\text { aeruginosa }\end{array}$} & \multirow{3}{*}{$\begin{array}{c}\text { Polymer } \\
\text { N2 }\end{array}$} & \multicolumn{5}{|c|}{ Halo values } & \multicolumn{3}{|c|}{ Variable correlations } \\
\hline & & \multicolumn{3}{|c|}{ Inhibition halo (mm) } & \multirow{2}{*}{$\begin{array}{c}\text { Mean } \\
0\end{array}$} & \multirow{2}{*}{$\begin{array}{c}\begin{array}{c}\text { Standard } \\
\text { deviation }\end{array} \\
0.0\end{array}$} & \multirow{2}{*}{$\frac{\mathbf{N} 2 *}{-}$} & \multirow{2}{*}{$\begin{array}{c}\text { N2-AS-Ag } \\
0.05935\end{array}$} & \multirow{2}{*}{$\begin{array}{r}\text { N2-SA-Ag } \\
0.04685\end{array}$} \\
\hline & & 0 & 0 & 0 & & & & & \\
\hline & N2-AS-Ag & 2 & 3 & 3 & 2.7 & 0.6 & 0.178 & - & 0.1876 \\
\hline & N2-SA-Ag & 2 & 2 & 2 & 2.0 & 0.0 & 0.1406 & 0.5629 & - \\
\hline \multirow[t]{3}{*}{ Escherichia coli } & $\mathrm{N} 2$ & 0 & 0 & 0 & 0 & 0.0 & - & 0.05935 & 0.04685 \\
\hline & N2-AS-Ag & 2 & 1 & 2 & 1.7 & 0.6 & 0.178 & - & 0.505 \\
\hline & N2-SA-Ag & 2 & 2 & 2 & 2.0 & 0.0 & 0.1406 & 1 & - \\
\hline
\end{tabular}

N2: PolyHIPE of styrene-divinylbenzene, N2-AS-Ag: Composite derived from polyHIPE N2 sulfonated with acetyl sulfate and impregnated with silver, N2-SA-Ag: Composite derived from polyHIPE N2 sulfonated with sulfuric acid and impregnated with silver. * $\mathrm{p}<0.05$ : statistically significant.

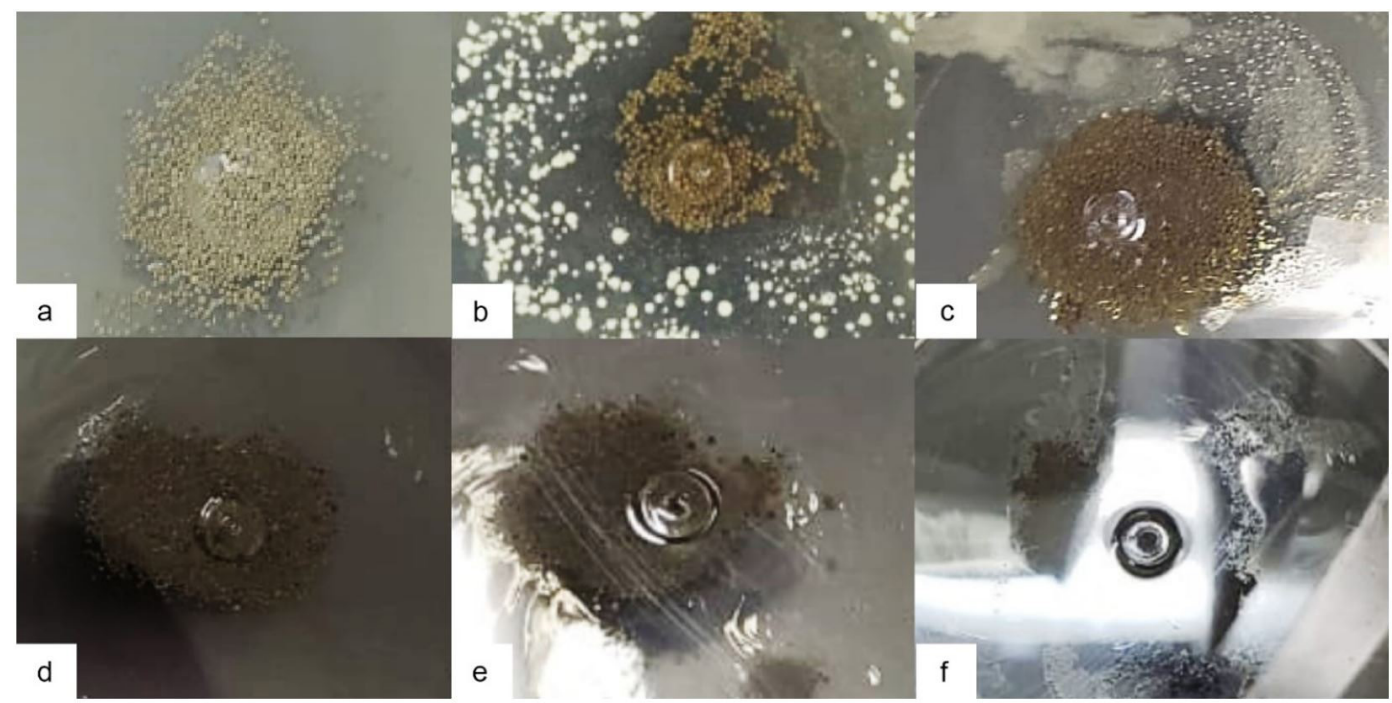

Figure 6. Silver composite derived from the commercial resin Dowex: (a) control; (b) presence of Staphylococcus aureus; (c) presence of Klebsiella variicola in bacterial adsorption and adhesion tests. Silver composites PoliHIPE N2: (d) control; (e) absence of Staphylococcus aureus; (f) absence of Klebsiella variicola in bacterial adsorption and adhesion tests.

difference in zone diameter was significant $(\mathrm{p}<0.05)$ only in the comparison between the composites derived from polyHIPE sulfonated with sulfuric acid and unmodified polyHIPEs. Tests showed that unmodified polyHIPEs and sulfonated materials did not have any antimicrobial activity, corroborating results previously published by Maria et al. ${ }^{[22]}$. Silver composites prepared from polyHIPEs sulfonated with sulfuric acid showed equal inhibition halos for the two bacteria (E. coli and P. aeruginosa), both Gram-negative. Data from thermogravimetry indicated that the composite derived from polyHIPE sulfonated with sulfuric acid presented higher content of silver than the composite derived from polyHIPE sulfonated with acetyl sulfate. The difference in zone diameter was not significant (Table 4).

Silver composites also were evaluated in relation to bacterial adsorption and adhesion by employing $K$. variicola (Gram-negative) and S. aureus (Gram-positive) (Figure 6). A silver composite derived from the commercial resin Dowex was used as reference in this test. It was possible to observe bacterial growth in the dishes containing composites derived Dowex. Dishes containing unmodified polyHIPEs and sulfonated materials also showed bacterial growth.
On the other hand, this bacterial growth was not observed in dishes containing silver composites, indicating absence of adsorption/adhesion of bacterial cells on the surface these materials. This test indicated that this material could prevent biofilm formation.

\section{Conclusions}

Silver composites were prepared by impregnation of silver particles in polyHIPEs of styrene-divinylbenzene. These polyHIPEs, with spherical shape, were prepared by aqueous suspension polymerization of high internal phase emulsions (HIPEs). Both particles produced had structures with macropores and low specific surface areas (18 and $48 \mathrm{~m}^{2} / \mathrm{g}$ ). PolyHIPEs were sulfated with sulfuric acid or acetyl sulfate and the sulfonation was confirmed by EDX, FT-IR and TGA. The cation exchange capacity (CEC) values of polyHIPEs sulfonated with sulfuric acid and acetyl sulfate were 4.03 and $5.07 \mathrm{meq} \mathrm{g}^{-1}$ respectively, indicating that sulfonation with sulfuric acid was more efficient. These sulfonated polymers presented similar CEC values in relation to commercial sulfonic resins 
with macroreticular structures. Also, the silver composite prepared from polyHIPE sulfonated with sulfuric acid had higher content of silver than that prepared with polyHIPE sulfonated with acetyl sulfate. Both composites presented similar inhibition halos against the bacteria $E$. coli and P. aeruginosa (Gram-negative bacteria). These composites also did not present adsorption/adhesion of bacterial cells of K. variicola (Gram-negative) and S. aureus (Gram-positive) on their surface, indicating these materials can be efficiently used to prevent biofilm formation.

\section{Acknowledgements}

We thank Fundação de Amparo a Pesquisa do Estado do Rio de Janeiro (FAPERJ), Nitriflex, Engepol/COPPE/ UFRJ, CETEM/UFRJ and Laboratório de Caracterização Instrumental III/IQ/UERJ.

\section{References}

1. Gokmen, M. T., \& Prez, F. E. (2012). Porous polymer particles - a comprehensive guide to synthesis, characterization, functionalization and applications. Progress in Polymer Science, 37(3), 365-405. http://dx.doi.org/10.1016/j.progpolymsci.2011.07.006.

2. Hainey, P., Huxham, I. M., Rowatt, B., Sherrington, D. C., \& Tetley, L. (1991). Synthesis and ultrastructural studies of styrene-divinylbenzene Polyhipe polymers. Macromolecules, 24(1), 117-121. http://dx.doi.org/10.1021/ma00001a019.

3. Cameron, N. R., \& Sherrington, D. C. (1996). High internal phase emulsions (HIPEs) Structure, properties and use in polymer preparation. In A. Abe, A. Albertsson, G. W. Coates, J. Genzer, S. Kobayashi, K. Lee, L. Leibler, T. E. Long, M. Möller, O. Okay, V. Percec, B. Z. Tang, E. M. Terentjev, P. Theato, B. Voit, U. Wiesner, \& X. Zhang (Eds.), Advances in Polymer Science: Biopolymers Liquid Crystalline Polymers Phase Emulsion (pp. 163-213). Berlin: Springer.

4. Desforges, A., Arpontet, M., Deleuze, H., \& Mondain-Monval, O. (2002). Synthesis and functionalization of polyHIPE beads. Reactive \& Functional Polymers, 53(2-3), 183-192. http:// dx.doi.org/10.1016/S1381-5148(02)00172-4.

5. Štefanec, D., \& Krajnc, P. (2005). 4-Vinylbenzyl chloride based porous spherical polymer supports derived from water-in-oilin-water emulsions. Reactive \& Functional Polymers, 65(1-2), 37-45. http://dx.doi.org/10.1016/j.reactfunctpolym.2005.01.007.

6. Štefanec, D., \& Krajnc, P. (2007). Aryl acrylate porous functional polymer supports from water-in-oil-in-water multiple emulsions. Polymer International, 56(10), 1313-1319. http:// dx.doi.org/10.1002/pi.2292.

7. Yang, Y., Liao, H., Tong, Z., \& Wang, C. (2015). Porous $\mathrm{Ag} /$ polymer composite microspheres for adsorption and catalytic degradation of organic dyes in aqueous solutions. Composites Science and Technology, 107, 137-144. http:// dx.doi.org/10.1016/j.compscitech.2014.12.015.

8. Mert, E. H., \& Hildirim, H. (2014). Porous functional poly(unsaturated polyester-coglycidyl methacrylate-codivinylbenzene) polyHIPE beads through w/o/w multiple emulsions: preparation, characterization and application. e-Polymers, 14(1), 65-73. https://doi.org/10.1515/epoly-2013-0071.

9. Cui, X., Shao, H., Song, Y., Yang, S., Wang, F., \& Liu, H. (2019). Preparation of highly interconnected porous polymer microbeads via suspension polymerization of high internal phase emulsions for fast removal of oil spillage from aqueous environments. RSC Advances, 9(44), 25730-25738. http:// dx.doi.org/10.1039/C9RA05220H.
10. Torquato, E. C. C., Brito, A. P. N., Trovão, R. S., Oliveira, M. A., Smith, N. S., Pinto, M. C. C., Pinto, J. C., Cipolatti, E. P., Freire, D. M. G., Marques, M. R. C., \& Costa, L. C. (2020). Synthesis of porous polymeric supports with polyHIPE structures based on styrene-divinylbenzene copolymers. Macromolecular Symposia, 394(1), 2000109. http://dx.doi. org/10.1002/masy.202000109.

11. Li, N., \& Benson, J. R. (1996). US Patent No 5583162 A. Washington: U.S. Patent and Trademark Office. Retrieved in 2021, September 06, from https://patents.google.com/patent/ US5583162A/en

12. Kitagawa, N. (2000) US Patent No 6048908A. Washington: U.S. Patent and Trademark Office. Retrieved in 2021, September 06, from https://patents.google.com/patent/US6048908A/en

13. Li, N., Benson, J. R., \& Kitagawa, N. (2000). US Patent No 6100306A. Washington: U.S. Patent and Trademark Office. Retrieved in 2021, September 06, from https://patents.google. com/patent/US6100306A/en

14. Kitagawa, N. (2001) US Patent No 6218440B1. Washington: U.S. Patent and Trademark Office. Retrieved in 2021, September 06, from https://patents.google.com/patent/US6218440B1/en

15. Koler, A., Paljevac, M., Cmager, N., Iskra, J., Kolar, M., \& Krajnc, P. (2017). Poly(4-vinylpyridine) polyHIPEs as catalysts for cycloaddition click reaction. Polymer, 126, 402-407. http:// dx.doi.org/10.1016/j.polymer.2017.04.051.

16. He, H., Li, W., Lamson, M., Zhong, M., Konkolewicz, D., Hui, C. M., Yaccato, K., Rappold, T., Sugar, G., David, N. E., Damodaran, K., Natesakhawat, S., Nulwala, H., \& Matyjaszewski, K. (2014). Porous polymers prepared via high internal phase emulsion polymerization for reversible $\mathrm{CO}_{2}$ capture. Polymer, 55(1), 385-394. http://dx.doi.org/10.1016/j. polymer.2013.08.002.

17. Su, R., Ruan, G., Nie, H., Xie, T., Zheng, Y., Du, F., \& Li, J. (2015). Development of high internal phase emulsion polymeric monoliths for highly efficient enrichment of trace polycyclic aromatic hydrocarbons from large-volume water samples. Journal of Chromatography. A, 1405, 23-31. http:// dx.doi.org/10.1016/j.chroma.2015.05.067. PMid:26077972.

18. Ruan, G., Wu, Z., Huang, Y., Wei, M., Su, R., \& Du, F. (2016). An easily regenerable enzyme reactor prepared from polymerized high internal phase emulsions. Biochemical and Biophysical Research Communications, 473(1), 54-60. http:// dx.doi.org/10.1016/j.bbrc.2016.03.049. PMid:26995089.

19. Costa, L. C., Mandu, M. A. L. G. M. R., Santa Maria, L. C., \& Marques, M. R. C. (2015). Resinas poliméricas reticuladas com ação biocida: atual estado da arte. Polímeros: Ciência e Tecnologia, 25(4), 414-423. http://dx.doi.org/10.1590/010414281739.

20. Mandu, M. A. L. G. M. R., Costa, L. C., Tiosso, R. B., Grasso, R. P., \& Calderari, M. R. C. M. (2019). Evaluation of antimicrobial action of silver composite microspheres based on styrene-divinylbenzene copolymer. Polímeros. Polímeros: Ciência e Tecnologia, 29(4), e2019052. http:// dx.doi.org/10.1590/0104-1428.00219.

21. Gangadharan, D., Harshvardan, K., Gnanasekar, G., Dixit, D., Popat, K. M., \& Anand, P. S. (2010). Polymeric microspheres containing silver nanoparticles as a bactericidal agent for water disinfection. Water Research, 44(18), 5481-5487. http://dx.doi. org/10.1016/j.watres.2010.06.057. PMid:20673945.

22. Maria, L. C. S., Oliveira, R. O., Mercon, F., Borges, M. E. R. S. P., Barud, H. S., Ribeiro, S. J. L., Messaddeq, Y., \& Wang, S. H. (2010). Preparation and bactericidal effect of composites based on crosslinked copolymers containing silver nanoparticles. Polimeros: Ciência e Tecnologia, 20(3), 227-230. http://dx.doi. org/10.1590/S0104-14282010005000028. 
23. Mthombeni, N. H., Mpenyana-Monyatsi, L., Onyango, M. S., \& Momba, M. N. B. (2012). Breakthrough analysis for water disinfection using silver nanoparticles coated resin beads in fixed-bed column. Journal of Hazardous Materials, 217-218, 133-140. http://dx.doi.org/10.1016/j.jhazmat.2012.03.004. PMid:22459979.

24. Ottens, M., Leene, G., Beenackers, A. A. C. M., Cameron, N., \& Sherrington, D. C. (2000). PolyHipe: a new polymeric support for heterogeneous catalytic reactions: kinetics of hydration of cyclohexene in two- and three-phase systems over a strongly acidic sulfonated polyHipe. Industrial \& Engineering Chemistry Research, 39(2), 259-266. http://dx.doi.org/10.1021/ie990452o.

25. Cohen, N., Samoocha, D. C., David, D., \& Silverstein, M. S. (2013). Carbon nanotubes in emulsion-templated porous polymers: polymer nanoparticles, sulfonation, and conductivity. Journal of Polymer Science. Part A, Polymer Chemistry, 51(20), 4369-4377. http://dx.doi.org/10.1002/pola.26851.

26. Cameron, N. R., Sherrington, D. C., Ando, I., \& Kurosu, H. (1996). Chemical modification of monolithic poly(styrenedivinylbenzene) polyHIPE $®$ materials. Journal of Materials Chemistry, 6(5), 719-726. http://dx.doi.org/10.1039/JM9960600719.

27. Rezende, S. M. (2006). Desenvolvimento de catalisadores poliméricos com grupos ativos sulfônicos (Doctoral thesis). Universidade Federal do Rio de Janeiro, Rio de Janeiro.

28. Oliveira, A. J. B., Aguiar, A. P., Aguiar, M. R. M. P., \& Maria, L. C. S. (2005). How to maintain the morphology of styrenedivinylbenzene copolymer beads during the sulfonation reaction. Materials Letters, 59(8-9), 1089-1094. http://dx.doi. org/10.1016/j.matlet.2004.12.014.

29. Santos, A. L. C. (2009). Síntese, caracterização e avaliação de materiais poliméricos com propriedades bactericidas (Master's dissertation). Universidade do Estado do Rio de Janeiro, Rio de Janeiro.

30. American Society for Testing and Materials-ASTM. (1975). ASTM D 1895-69: Annual Book of ASTM. West Conshohocken: ASTM.

31. Sing, K. S. W., Everett, D. H., Haul, R. A. W., Moscou, L., Pierotti, R. A., Rouquerol, J., \& Siemieniewska, T. (1985). Reporting physisorption data for Gas/Solid systems with special reference to the determination of surface area and porosity (Recommendations 1984). Pure and Applied Chemistry, 57(4), 603-619. http://dx.doi.org/10.1351/pac198557040603.

32. Reis, S. C. M., Lachter, E. R., Nascimento, R. S. V., Rodrigues, J. A., Jr., \& Reid, M. G. (2005). Transesterification of Brazilian vegetable oils with methanol over ion-exchange resins. Journal of the American Oil Chemists 'Society, 82(9), 661-665. http:// dx.doi.org/10.1007/s11746-005-1125-y.

33. Bauer, A. W., Kirby, W. M. M., Sherris, J. C., \& Turck, M. (1966). Antibiotic susceptibility testing by standardized single disk method. American Journal of Clinical Pathology, 45(4), 493-496. http://dx.doi.org/10.1093/ajcp/45.4_ts.493. PMid:5325707.

34. Budhlall, B. M., Landfester, K., Sudol, E. D., Dimonie, V. L., Klein, A., \& El-Aasser, M. S. (2003). Characterization of partially hydrolyzed poly(vinyl alcohol). Effect of poly(vinyl alcohol) molecular architecture on aqueous phase conformation. Macromolecules, 36(25), 9477-9484. http://dx.doi.org/10.1021/ ma030027d.

35. Okay, O. (2000). Macroporous copolymer networks. Progress in Polymer Science, 25(6), 711-779. http://dx.doi.org/10.1016/ S0079-6700(00)00015-0.

36. Zheng, Y., Wang, Q., Yang, C., \& Qiu, T. (2019). Experimental study on mass transport mechanism in poly (styrene-codivinylbenzene) microspheres with hierarchical pore structure. Chemical Engineering and Processing - Process Intensification, 139, 183-192. https://doi.org/10.1016/j.cep.2019.03.016.

37. Coutinho, F. M. B., Rezende, S. M., \& Soares, B. G. (2006). Characterization of sulfonated Poly(styrene-divinylbenzene) and Poly(divinylbenzene) and its application as catalysts in esterification reaction. Journal of Applied Polymer Science, 102(4), 3616-3627. http://dx.doi.org/10.1002/app.24046.

38. Simplicio, S., Lucas, E. F., Costa, M. A. S., Costa, L. C., \& Maria, L. C. S. (2014). Thermal resistance of magnetic polymeric composites based on styrene, divinylbenzene and $\mathrm{Ni}$ and $\mathrm{Co}$ particles. Journal of Thermal Analysis and Calorimetry, 117(1), 369-375. http://dx.doi.org/10.1007/s10973-014-3703-9.

39. Aguiar, V. M., Souza, A. L. F., Galdino, F. S., Silva, M. M. C., Teixeira, V. G., \& Lachter, E. R. (2017). Sulfonated poly(divinylbenzene) and poly(styrene-divinylbenzene) as catalysts for esterification of fatty acids. Renewable Energy, 114, 725-732. http://dx.doi.org/10.1016/j.renene.2017.07.084.

40. Rezende, S. M., Reis, M. C., Reid, M. G., Silva, P. L., Jr., Coutinho, F. M. B., San Gil, R. A. S., \& Lachter, E. R. (2008). Transesterification of vegetable oils promoted by poly(styrenedivinylbenzene) and poly(divinylbenzene). Applied Catalysis A, General, 349(1-2), 198-203. http://dx.doi.org/10.1016/j. apcata.2008.07.030.

41. Andrijanto, E., Dawson, E. A., \& Brown, D. R. (2012). Hypercrosslinked polystyrene sulphonic acid catalysts for the esterification of free fatty acids in biodiesel synthesis. Applied Catalysis B: Environmental, 115-116, 261-268. http://dx.doi. org/10.1016/j.apcatb.2011.12.040.

Received: Feb. 12, 2021

Revised: Sep. 06, 2021

Accepted: Oct. 28, 2021 


\section{Supplementary Material}

Supplementary material accompanies this paper.

Figure S1. Optical microscopy of polyHIPE N3. Magnification of 50x

Figure S2. Optical microscopies of the Sty-DVB polyHIPE N2 (a) before (b) after sulfonation reaction with sulfuric acid. Magnification of $50 \mathrm{x}$

Table S1. Cation exchange capacity (CEC) of the polyHIPE sulfonated with acetyl sulfate (N2-AS), polyHIPE sulfonated with sulfuric acid (N2-SA) and other sulfonic resins reported in the literature

This material is available as part of the online article from https://www.scielo.br/j/po 